\title{
Bioactivation of nitroglycerin by the East Asian variant of aldehyde dehydrogenase-2
}

\author{
Matteo Beretta*1, Antonius CF Gorren ${ }^{1}$, M Verena Wenzl ${ }^{1}$, Robert Weis², \\ Michael Russwurm ${ }^{3}$, Doris Koesling ${ }^{3}$, Kurt Schmidt ${ }^{1}$ and Bernd Mayer ${ }^{1}$
}

\author{
Address: ${ }^{1}$ Department of Pharmacology and Toxicology, Karl-Franzens-Universität Graz, 8010 Graz, Austria, ${ }^{2}$ Department of Pharmaceutical \\ Chemistry, Karl-Franzens-Universität Graz, 8010 Graz, Austria and ${ }^{3}$ Department of Pharmacology and Toxicology, Ruhr-Universität Bochum, \\ 44780 Bochum, Germany \\ Email: Matteo Beretta* - matteo.beretta@uni-graz.at \\ * Corresponding author
}

\author{
from 4th International Conference of cGMP Generators, Effectors and Therapeutic Implications \\ Regensburg, Germany. 19-21 June 2009 \\ Published: II August 2009 \\ BMC Pharmacology 2009, 9(Suppl I):P3 doi:10.1 186/147I-2210-9-SI-P3
}

This abstract is available from: http://www.biomedcentral.com/I47I-22I0/9/SI/P3

(C) 2009 Beretta et al; licensee BioMed Central Ltd.

\section{Background}

The East Asian variant of mitochondrial aldehyde dehydrogenase (ALDH2) exhibits significantly reduced dehydrogenase, esterase and nitroglycerin (GTN) reductase activities [1]. The small molecule Alda-1 was reported to partly restore low acetaldehyde dehydrogenase activity of this variant [2]. In the present study we compared the wild type enzyme $\left(\mathrm{ALDH} 2{ }^{*} 1\right)$ with the East Asian variant $(\mathrm{ALDH} 2 * 2)$ regarding GTN bioactivation and effects of Alda-1.

\section{Results}

Alda-1 increased acetaldehyde oxidation by ALDH2*1 and $\mathrm{ALDH} 2 * 2$ about 2 - and 15 -fold, respectively. The effects of this compound on the esterase activities of both enzymes were identical to that of NAD (6- and 10-fold stimulation with ALDH2* 1 and $\operatorname{ALDH} 2 * 2$, respectively), but in the presence of the nicotinamide Alda- 1 stimulated the esterase activity of ALDH $2 * 1$ only 1.7 -fold, whereas the ALDH2*2-catalyzed reaction was increased 73-fold.

ALDH2* 1 exhibited a greater affinity for GTN than ALDH2*2 (with $K_{m}$ values of $7.6 \pm 1.4$ and $54 \pm 6 \mu \mathrm{M}$, respectively) as well as a 7 -fold higher maximal GTN denitration activity. However, bioactivation of the nitrate, measured as soluble guanylate cyclase (sGC) activation, was much more pronounced $(8.8 \pm 0.2$ and $18.2 \pm 0.9$ $\mu \mathrm{mol}$ cGMP $\times \min ^{-1} \times \mathrm{mg}^{-1}$ in the presence of $100 \mu \mathrm{g} / 100$ $\mu \mathrm{L}$ ALDH2 and $100 \mu \mathrm{M}$ GTN). Alda-1 caused $30-70 \%$ inhibition of GTN denitration by ALDH $2 * 1$ but had no effect on the ALDH $2 * 2$-catalyzed reaction and did not affect GTN-induced sGC activation in the presence of either variant.

\section{Conclusion}

The present results indicate that Alda-1 stimulates established ALDH2 activities by improving NAD binding but does not restore impaired GTN bioactivation by the East Asian variant. In addition, our data revealed an unexpected discrepancy between GTN reductase activity and sGC activation, suggesting that GTN denitration and bioactivation reflect independent reactions catalyzed by ALDH2.

\section{Acknowledgements}

Supported by Fonds zur Förderung der Wissenschaftlichen Forschung in Austria (W90I DK Molecular Enzymology and P20669) and Deutsche Forschungsgemeinschaft (KOII57/4-I).

\section{References}

I. Larson HN, Zhou J, Chen Z, Stamler JS, Weiner H, Hurley TD: Structural and functional consequences of coenzyme binding to the inactive Asian variant of mitochondrial aldehyde dehydrogenase. J Biol Chem 2007, 282: 12940-I2950.

2. Chen CH, Budas GR, Churchill EN, Disatnik MH, Hurley TD, MochlyRosen D: Activation of aldehyde dehydrogenase-2 reduces ischemic damage to the heart. Science 2008, 321: | 493-| 495. 